\title{
O CONCEITO KANTIANO DE MÁXIMA E A SOLUÇÃO DA ANTINOMIA DA FACULDADE DE JULGAR TELEOLÓGICA NA TERCEIRA CRÍTICA
}

Renato Valois CORDEIRO ${ }^{1}$

- RESUMO: O presente artigo visa explicar o conceito kantiano de máxima. Seu propósito é aduzir uma interpretação capaz de identificar as diferentes funções deste conceito na filosofia de Kant. Além disso, o autor explora as consequências da sua análise na esfera da solução da antinomia da faculdade de julgar teleológica na terceira Crítica. No cerne desta antinomia está a alegação de Kant, segundo a qual toda a "aparência" (Anschein) de conflito entre as máximas mecânica e teleológica provém da confusão de um princípio da faculdade de julgar reflexiva com um princípio da faculdade de julgar determinante.

- PALAVRAS-CHAVE: Filosofia prática; filosofia teórica; filosofia transcendental; imperativos; julgar reflexivo; máximas; princípios práticos objetivos; princípios práticos subjetivos.

Um dos pilares de uma proposta de solução da antinomia da faculdade de julgar teleológica que não represente uma revisão da posição de Kant (relativamente ao que ele próprio havia desenvolvido na Crítica da Razão Pura-CRP) consistiria em mostrar que o princípio da causalidade natural, que compõe o conflito juntamente com o princípio da finalidade real (ou objetiva), não está sendo tomado na Crítica da Faculdade de Julgar-CFJ no mesmo sentido que o era na primeira Crítica. Ou seja, seria preciso mostrar que o mesmo princípio de causalidade natural da CRP funciona na $C F J$ e é tomado no capítulo da antinomia com um uso distinto, a saber, como um princípio regulador da faculdade de julgar reflexiva - e não como um princí-

1 Doutor em Filosofia pela Universidade Federal do Rio de Janeiro-UFRJ e docente na rede privada do Rio de Janeiro. 
pio constitutivo do entendimento, o que mostraria que não houve qualquer passo atrás por parte de Kant, já que tratar-se-ia da reutilização de uma mesma regra num outro contexto. Outra possibilidade seria demonstrar que as expressões "princípio de causalidade natural", que aparece na primeira Crítica, e "princípio de causalidade mecânica eficiente" (ou "princípio do mecanismo"), que é uma das utilizadas por Kant na CFJ, não são sinonímicas. Nesse caso seria preciso argumentar no sentido de mostrar que o princípio mecânico da CRP tem uma forma diferente do princípio mecânico aduzido na terceira. Esta foi precisamente a minha opção interpretativa na tese de doutoramento.

Uma das evidências textuais para mostrar que o princípio da causalidade natural é tomado no contexto da antinomia como um princípio regulador da faculdade de julgar se encontra já no parágrafo 69 da CFJ. Ele introduz, por sinal, a problemática do conflito. Com efeito, Kant começa argumentando que não pode haver uma antinomia da faculdade de julgar no seu uso determinante, pelo simples fato de que ela não tem princípios próprios, uma vez que se limita a determinar um particular lançando mão de um princípio ou regra dado em outra parte. Ou seja, como ele diz, a faculdade de julgar determinante "não está exposta a qualquer perigo de uma antinomia que lhe seja específica e a qualquer conflito dos seus princípios (ist keiner Gefahr ihrer eigenen Antinomie und keinem Widerstreit ausgesetzt)" (Kant 1, V: 385; negrito nosso). Assim, se é possível uma autêntica antinomia da faculdade de julgar, somente na medida em que as regras em conflito forem provenientes dela própria. Ora, mas isso só pode acontecer no caso do uso reflexivo da faculdade de julgar, posto que, nesse caso, a sua atividade é regulada por princípios que ela não tira de outra parte, mas sim de si. Só assim pode haver, por assim dizer, uma eigene antinomia da faculdade de julgar. Dessas afirmações iniciais de Kant podemos depreender que quando o princípio de causalidade for mais à frente nomeado como componente da antinomia da faculdade de julgar, ele só o pode estar sendo na qualidade de um princípio regulativo da faculdade de julgar - e não como um princípio constitutivo do entendimento - como o era na primeira Crítica.

O problema sutil criado por Kant no contexto dessa argumentação está em que, tomado como uma das regras reguladoras de um conflito antinômico da faculdade de julgar reflexiva, ou seja, como uma máxima, parece ao leitor atento e minimamente conhecedor da filosofia crítica, que na verdade não foi produzida nenhuma antinomia. Pois como pode haver uma antinomia entre máximas regulativas? A solução para essa dificuldade interpretativa está em mostrar que pelo menos há nesse caso uma autêntica aparência de antinomia da faculdade de julgar reflexiva, aparência ou ilusão causada pelo filósofo dogmático que não compreende que ambos os princípios são igualmente meras máximas da reflexão - e não princípios constitutivos. 
Uma exposição adequada a respeito da solução da antinomia da faculdade de julgar teleológica supõe, portanto, uma compreensão clara da distinção entre princípios constitutivos (que podem ser críticos ou dogmáticos) e princípios regulativos (transcendentais), tão fundamental na esfera da filosofia crítica. O objetivo central deste artigo é tratar de uma espécie de princípio regulativo, representada pelo conceito kantiano de máxima. Veremos que ele pode ser empregado tanto no âmbito da filosofia prática como na esfera da filosofia teórica.

Todos os principais comentaristas da antinomia da faculdade de julgar teleológica dão a entender que a sua solução envolve essencialmente dois momentos. O primeiro deles estaria presente já na sua apresentação, onde Kant estaria evitando uma suposta contradição entre os princípios envolvidos, apresentando ambos como máximas, considerando desse modo as duas posições como exemplos de regras regulativas.

O segundo momento da solução consistiria numa referência a um teoricamente possível fundamento noumenal da natureza. Ou seja, em tese, mesmo fins naturais podem ser pensados sem contradição como possíveis (ou explicáveis) a partir de princípios puramente mecânicos de um ponto de vista noumenal. Nesse sentido, uma vez que as máximas mecânica e teleológica representam somente o modo como refletimos sobre determinados fenômenos, não pode ser afastada a hipótese de um ponto de vista diverso. Assim, pode-se pensar sem contradição num ser cujo conhecimento está sujeito a condições ontológicas (Allison 1, cap. 1), ou que tem como característica um intelecto que assimila condições epistêmicas a condições ontológicas - e, desta forma, que tem noumena como seus objetos. Kant de fato contrasta metodologicamente na "Dialética da Faculdade de Julgar Teleológica" (Kant 1, V: 406-7-8) o intelecto humano com aquele que denomina "intelecto intuitivo". É um artifício simplesmente crítico, através do qual são destacadas as peculiaridades do entendimento finito (humano). De acordo com a CFJ, o conceito de conhecimento discursivo, característico do nosso intelecto, tem como nota a contingência do acordo entre universais e particulares, uma vez que estes estão fundados na sensibilidade, enquanto aqueles no entendimento, o qual tem uma função absolutamente heterogênea. Não surpreende, aliás, que Kant tenha introduzido em sua teoria o conceito de finalidade, que, do ponto de vista formal, é necessariamente pensado pelo entendimento finito. Diferentemente do intelecto intuitivo, o nosso conhecimento só tem acesso a particulares enquanto instâncias de conceitos. Por este motivo, Kant afirma que o intelecto finito parte no processo cognitivo do "analítico-universal" para o particular. Diferen- 
temente, o "intelecto intuitivo" caminha no sentido "universal-sintético" (i. é da intuição de noumena como partes de um todo) para o particular. É digno de nota que contingência e finalidade não são notas do conceito de intelecto intuitivo, uma vez que este, por hipótese, só conhece coisas-em-si. Portanto, para um intelecto assim não existiria qualquer utilidade para a distinção entre causalidade mecânica e causalidade final, razão pela qual não é logicamente impossível pensar que numa perspectiva noumenal organismos possam ser (totalmente) explicados mecanicamente.

Muito embora alguns dos intérpretes mais autorizados da antinomia da faculdade de julgar teleológica vejam nesses dois passos elementos decisivos para a sua solução, parece-me que somente o primeiro é de fato relevante. A distinção crítica entre entendimentos discursivo e intuitivo é útil sobretudo para ratificar, por um lado, que o princípio da finalidade formal é uma condição necessária para a atividade de conhecer de um intelecto finito, o qual tem de produzir conceitos empíricos para fazer juízos objetivos - em outras palavras, a distinção é útil para mostrar que o conceito de finalidade tem de ser uma nota do conceito de intelecto discursivo. Por outro lado, o reconhecimento de que a faculdade de julgar em seu uso reflexivo tem um princípio próprio serve para garantir que duas interpretações dogmáticas desse princípio podem gerar um conflito antinômico real. Mas, uma vez admitida a existência de uma antinomia da faculdade de julgar, vejo que a querela em torno da sua solução deve se ater a questões do tipo: é possível existir uma antinomia entre máximas, que são princípios definidos como regras regulativas? Ou: Kant está de fato apresentando uma antinomia no parágrafo 70 ? As duas posições são efetivamente contraditórias e excludentes, sendo expressas por máximas da faculdade de julgar reflexiva? Alguns comentaristas julgaram sem maiores questionamentos que há uma efetiva antinomia na suposta contradição entre princípios subjetivos introduzida por Kant na "Dialética da Faculdade de Julgar Teleológica". Nos parágrafos seguintes mostrarei alguns pontos que devem ser levados em consideração nas respostas a essas perguntas. Surpreendentemente, a maioria deles permanece intocada nas interpretações fornecidas para a solução da antinomia, e, a meu juízo, todos estão relacionados diretamente ao modo como Kant define o seu conceito geral de máxima.

A definição desse conceito é introduzida por Kant já na $C R P$ e utilizada amplamente sobretudo no contexto da sua filosofia prática. De qualquer modo, nos dois casos, isto é tanto na esfera da filosofia teórica como no âmbito da filosofia moral, uma máxima deve ser sempre definida como uma regra que tem validade subjetiva.

O primeiro significado do conceito remete à filosofia teórica, mais especificamente ao papel que as idéias do incondicionado (excluídas de qualquer uso dogmático) representam na ampliação da experiência. Neste caso 
o uso dos conceitos da razão se expressa precisamente em principios subjetivos que funcionam, por assim dizer, impulsionando o conhecimento. Desta forma, no conhecimento empírico o cientista é sempre guiado por tais principios ao buscar um objeto hipotético que ele sabe que não alcançará - ou seja, o incondicionado. Não há qualquer erro nisto porque o cientista sabe que suas máximas não designam um objeto, mas sim a tarefa de procurá-lo, ou seja, uma mera regra de como proceder. Por isto, um princípio da ampliação maior possível da experiência é meramente subjetivo no sentido de que ele legisla apenas para o sujeito - e não para a totalidade dos objetos, ou seja, para natureza.

Além disso, na CRP a razão desempenhava uma função mais sutil que seria posteriormente atribuída à faculdade de julgar em seu uso reflexivo na terceira Crítica. Segundo a minha interpretação, as máximas da razão tinham no "Apêndice à Dialética Transcendental" (Kant 1, III: 349) um papel decisivo não apenas na busca da ampliação do conhecimento, mas também na função de sistematização do conhecimento. Nesse sentido, os princípios da afinidade, da generalização e da especificação representavam máximas que eram, como o princípio da finalidade formal da CFJ, condições de possibilidade do conhecimento. Visto que regras constitutivas são regras para atos ou atividades que não podem ser definidas independentemente da enunciação dessas regras, e regras regulativas são regras para atos ou atividades que podem ser definidas sem a menção das regras, podemos caracterizar sem problemas as máximas da filosofia teórica (entre elas as máximas que constituem a antinomia da faculdade de julgar teleológica) como espécies de regras regulativas - uma vez que, neste âmbito, esses princípios não erguem qualquer pretensão relativamente à constituição da objetualidade dos objetos da natureza.

Na esfera prática a definição de máxima ainda envolve a caracterização de uma regra com validade subjetiva. Entretanto, máximas têm na filosofia moral um significado mais complexo, relacionado a um outro uso da expressão que pode ser um tanto equívoco. É possível afirmar então que as definições do conceito de máxima na filosofia teórica e na filosofia prática são análogas, porém diferentes sob certos aspectos. Nesse sentido, as definições num e noutro campo realmente se aproximam na medida em que expressam regras subjetivas. Contudo elas se distanciam no que tange ao caráter constitutivo que certas máximas podem desempenhar na esfera ética. Com o objetivo de explicitar um segundo sentido para o predicado subjetivo quando este é compreendido como uma nota do conceito kantiano de máxima, farei no parágrafo seguinte um excurso à teoria apresentada na Fundamentação da Metafísica dos Costumes-FMC, que é mantida sob muitos aspectos na Crítica da Razão Prática. 
Na FMC, Kant define o conceito de vontade humana como a capacidade que temos de agir com base em regras da razão as quais formulamos como imperativos. Esse conceito de vontade (ou querer (Wollen)), na medida em que implica a formulação de proposições que orientam o agir através da prescrição daquilo que nos é representado com sendo bom, envolve também a adoção de justificativas. Por isso, o exercício dessa capacidade requer não apenas o poder de representar proposicionalmente - isto é julgar - o que nos parece bom fazer, mas requer tambem a adoção das proposições que representam o que queremos fazer.

Na medida em que são escolhidas e adotadas, tais proposições são denominadas por Kant leis do querer, ou simplesmente máximas (Maximen). Proposições práticas que representam máximas trazem sempre a representação de motivos que caracterizam as razões para agir escolhidas pelo agente racional finito, sejam elas meramente prudenciais, sejam elas morais. Portanto, a definição kantiana do conceito de motivo (Triebfeder / Bewegungsgrund) (Kant 1, IV: 427) relaciona-o diretamente ao conceito de subjetividade. Quero dizer que motivos só podem ser caracterizados como estímulos para a adoção de regras que dizem o que quer fazer um agente racional imperfeito particular na medida em que são (1) compreendidos (representados proposicionalmente) e (2) incorporados numa máxima. Somente desta maneira tem sentido afirmar rigorosamente que um determinado agente tem razões para a realização de uma escolha. Por isso é correto afirmar que uma máxima é um princípio prático subjetivo, isto é que determina o agir segundo as condições do sujeito - e é, portanto, em última análise, o princípio segundo o qual o sujeito age. É essencial notar que a expressão subjetivo, quando aplicada ao conceito prático de máxima, pode assumir dois significados precisos:

[a] Pode fazer referência à representação de motivos contingentes, isto é aos motivos incorporados em máximas condicionais. Pode se referir, portanto, a meras representações sensíveis.

[b] Pode se referir ao reconhecimento da lei moral na medida em que ele está incorporado como motivo de um agir numa máxima (cf., p. ex., Bittner 1).

Como se sabe, Kant utiliza a expressão lei moral para designar princípios práticos objetivos, que consistem em regras práticas universalmente válidas. Com efeito, a fórmula, por assim dizer, de todas as proposições práticas objetivas não pode prescrever classes de objetos para o agir racional; ela se expressa num princípio formal, a priori, portanto independente de qualquer sentimento ligado ao prazer. Relativamente a um ser racional finito, dotado de uma sensibilidade, como o homem, princípios práticos objeti- 
vos são representados a título de obrigações incondicionais. A fórmula objetiva de determinação da vontade humana, que confere a forma desses tipos de obrigações é denominada por Kant imperativo categórico. Conversamente, princípios práticos que representam ações boas, mas unicamente enquanto meios para o alcance de fins estritamente particulares (empíricos), nos aparecem como imperativos hipotéticos (ou condicionados). Assim, máximas, isto é princípios práticos subjetivos podem sem contradição ou bem representar imperativos hipotéticos, ou bem imperativos morais. No primeiro caso, descrito em [a], o predicado subjetivo refere-se então às representações sensíveis que motivam máximas condicionais. No caso [b] o mesmo predicado refere-se aos motivos morais quando adotados pelo agente numa máxima incondicional. Nos dois casos o predicado subjetivo caracteriza o fato de que a adoção de uma máxima depende sempre do sujeito, ou do agente racional finito. No caso [a], contudo, o conceito é mais amplo e é tambem sinonímico ao conceito de um predicado empírico - já que deve indicar que uma máxima condicionada foi escolhida por um determinado sujeito.

Diante do que foi dito acima, pode-se compreender por que máximas são sempre subjetivas, sejam elas máximas da filosofia teórica, sejam elas máximas utilizadas dentro do quadro categorial da filosofia prática. Entretanto, ainda não está claro o que distancia os conceitos de máxima nas duas esferas.

Entendo que os conceitos teórico e prático se afastam no que tange ao fato de que enquanto máximas desempenham sempre a função de regras subjetivas, porém sempre regulativas e transcendentais na filosofia teórica, na filosofia prática elas podem ter em certo sentido a função de regras constitutivas. Obviamente, no âmbito prático são as ações, entendidas como objetos da vontade, que são tornadas possíveis por um conceito, ou seja, a idéia de moralidade. Na medida em que juízos que dizem o que devemos fazer não podem ser pensados como determinados causalmente, eles têm sempre de ser feitos (como aliás qualquer juízo) e supõem para tanto a espontaneidade do nosso poder de realizar escolhas. Ora, o conceito de razão prática se refere ao poder do agente de determinar o seu querer através de princípios práticos. Este poder, é claro, se expressa em juízos práticos a título de máximas. É claro que, se a razão prática (ou vontade) é capaz de estabelecer princípios práticos puros (ou objetivos), podemos nos referir a tal faculdade com a denominação razão prática pura. Neste caso, a razão prática deve ser capaz de conter a regra para a constituição de juízos práticos incondicionais para a determinação da vontade (Kant 1, V: 16). Pode-se afirmar então que juízos práticos objetivos adotados como máximas expressam objetos da vontade constituídos pela razão prática pura. Evidentemente, compreender máximas da filosofia prática como regras constitutivas exclui qualquer uso da razão 
prática para a constituição crítica ou dogmática de conhecimentos, vale dizer, qualquer uso da vontade como faculdade cognitiva.

Esses esclarecimentos, ainda que sumários, acerca do conceito kantiano de máxima sempre foram contudo negligenciados pelos intérpretes da antinomia da faculdade de julgar teleológica. Mas eles são absolutamente necessários para sabermos (1) se de fato existe uma antinomia da faculdade de julgar e, aceito isto, para sabermos (2) se o primeiro passo da solução da antinomia (atribuído a Kant por alguns de seus intérpretes) de fato contribui para resolver o conflito. Pois, por um lado, só pode haver uma antinomia da faculdade de julgar se as posições da pretensa antinomia, representadas por máximas regulativas e transcendentais puderem representar de fato posições contraditórias e excludentes. Por outro lado, se tais máximas representam na verdade a solução de um outro conflito antinômico, na medida em que compatibilizariam assim tese e antítese do conflito, isso tem de ser demonstrado. Portanto, tanto o tipo de argumentação que visa justificar a existência de uma antinomia entre princípios regulativos da faculdade de julgar (Cf. por exemplo, Hegel 1, p.442-3 e McLaughlin 1, p.127), como a argumentação que visa resolver uma outra antinomia através da transformaÇão das suas proposições dogmáticas em máximas regulativas, tem de explicar antes como (ou se) máximas podem (ou não) se contradizer.

Em em seu livro (Butts 1, p.272-3), Butts afirma que princípios regulativos não podem se contradizer porque eles não têm uma forma proposicional. Se compreendi bem as afirmações feitas por esse intérprete, o seu argumento baseia-se em certas objeções (cf., p. ex., Patzig 1) à aplicação de categorias lógicas a proposições práticas (por exemplo, a caracterização kantiana dos imperativos morais como proposições sintéticas a priori, ou a designação de imperativos hipotéticos como juízos analíticos) e, em particular, à utilidade da aplicação do princípio da contradição para explicar a possibilidade de oposições exclusivas entre máximas de um modo geral. No que segue farei uma longa digressão com o objetivo de defender que, num certo sentido, que é a meu ver o aplicado à solução da antinomia da faculdade de julgar teleológica, máximas regulativas de fato não podem se contradizer. Mostrarei, portanto, que a afirmação de Butts sobre princípios regulativos é realmente válida com base em certas condições, as quais, entretanto, ele não tematiza em seu trabalho.

Como se sabe, antes da FMC expressões como categórico, hipotético, analítico e sintético eram aplicadas apenas, para usar uma expressão aristotélica, a frases apofânticas, que linguisticamente equivalem a frases enunciativas ou assertóricas (em alemão, Aussagesaetze). A função expressiva desse tipo de frases consiste sobretudo num apresentar, isto é em dizer que algo é ou não o caso de um conceito (Tugendhat 1, cap. 2). Com relação a elas, com efeito, pode-se perguntar se a mesmas são verdadeiras ou falsas 
e, nesse sentido, frases assertóricas devem ser distinguidas, por exemplo, de imperativos, uma vez que asserções erguem sempre uma pretensão de verdade. Por isso podemos perguntar se um juízo deste tipo é verdadeiro ou falso, o que quer dizer indagar se a pretensão de verdade erguida está ou não fundamentada.

Creio que a crítica à aplicação de certos termos lógicos a proposições práticas tem em parte algum sentido, já que esse procedimento de fato pode apresentar uma certa equivocidade, o que requer, portanto, algumas justificativas. Entretanto, a restrição da validade do princípio da contradição apenas para explicitar oposições entre juízos que têm a propriedade de ser verdadeiros ou falsos, isto é que têm valor de verdade, parece-me equivocada. Vejamos primeiramente o caso da aplicação de predicados lógicos a juízos práticos.

Relativamente a seres imperfeitamente racionais, como é caso do homem, proposições práticas são representadas a título de mandamentos (Gebote), que nos são representados como imperativos. Muito embora em sentido lato seja possível falarmos de juízos práticos, é preciso distinguir rigorosamente o conceito estrito de juízo do conceito de imperativo. Com efeito, este jamais pode ser propriamente verdadeiro ou falso. Mas do termo juízo faz-se um uso muitas vezes ambíguo, que por vezes diz respeito a um sentido meramente psicológico - quando significa apenas o julgar como um ato psíquico. Outras vezes o termo remete entretanto ao julgado, quando se refere aproximadamente à proposição (Satz), dizendo respeito neste sentido à fundamentação de juízos cognitivos. Por conseguinte, juízos teóricos (objetivos), cujas formas foram apresentados na famosa tábua dos juízos da $C R P$, podem representar para o sujeito o reconhecimento da verdade (ou não) de uma proposição (ou enunciado). Nesse sentido, juízos (Urteile) podem ou bem representar proposições (Saetze) com mera possibilidade lógica, que carecem ainda de fundamentação (nicht begruendet) - seria o denominado por Kant nicht behauptete Urteile ou problematische Urteile -, ou bem proposições com possibilidade lógica e real (validade objetiva), que representam para Kant behauptete Urteile ou assertorische Urteile, isto é juízos, ou proposições, já fundamentados (begruendet) (Patzig, p.1, n. 1).

O termo lógico categórico foi utilizado originalmente para se referir a frases apofânticas, ou seja, a frases construídas com a estrutura sujeito/predicado, portanto a juízos que erguem uma pretensão de verdade. O termo lógico hipotético, também utilizado por Kant na filosofia prática para se referir a certos imperativos, é aplicado originalmente a hypotetische Urteile (Kant 1, III: 88), isto é a juízos que representam a relação premissa/consequência (Grund/Folge) existente entre dois (ou mais) juízos objetivos. Neste caso, duas proposições $p$ e q são ligadas logicamente através das expressões se-então de modo que uma terceira proposição resulta como conse- 
quência da relação. Antecipando a lógica moderna, a Lógica de Jaesche (Kant 1, IX: 105-6 (parágrafo 25, observação 2)) esclarece que é preciso distinguir o valor de verdade de cada uma das duas proposições envolvidas numa relação lógica desse tipo, do valor de verdade da proposição composta resultante (se $p$, então $q$ (wenn $p$, so q)). Este esclarecimento está contido - certamente de uma maneira pouco clara - na afirmação de que um juízo hipotético wenn $p$, so q expressa uma conclusão que contém uma "(.). problematisch ausgedrueckte Bedingung" (ibidem). Isso quer dizer que a proposição $q$ é afirmada sob a condição $p$. Portanto, nesse caso o conceito de implicação lógica pode ser reduzido ao conceito de verdade necessária apenas se as duas proposições envolvidas na relação forem de fato verdadeiras - ou, seguindo a afirmação de Kant na Lógica, apenas se o juízo problemático $p$ puder ser fundamentado, isto é se ele for verdadeiro. A verdade necessária do enunciado complexo resultante depende assim da relação entre os valores de verdade das proposições envolvidas no juízo hipotético considerado.

Retornando à nossa primeira questão central: em qual sentido Kant pode aplicar os termos lógicos categórico e hipotético a imperativos, que não são juízos cognitivos? No que tange especificamente a estes termos, a chave da resposta a esta pergunta pode ser depreendida da expressão problematisch ausgedrueckte Bedingung, mais propriamente no uso da expressão Bedingung (condição). Como já visto, imperativos hipotéticos são proposições práticas condicionais, cuja forma pode ser expressa atraves da fórmula se queres $x$, então faça $y$. Essa função proposicional á claramente análoga à dos juízos hipotéticos (se $p$, então q), muito embora represente uma relação distinta. Um imperativo hipotético não é um tipo de juízo hipotético-teórico que estabelece a ligação entre uma premissa e uma consequência (ou conclusão), as quais representariam respectivamente um interesse (ou fim particular) e o mandamento adequado que diz o que fazer em vista da realização deste interesse. Por isso pode-se afirmar que enquanto o juízo hipotético representa, como diz Patzig, um bedingtes Behaupten (Patzig, p.209), o imperativo hipotético é apenas uma proposição prática condicional ou uma bedingte Forderung. Conversamente, a formulação do imperativo categórico é válida para todo ser racional irrestritamente; sua obrigatoriedade não está ligada a qualquer desejo pressuposto e por isso tem validade universal e incondicional. Portanto, o uso das duas categorias lógicas em questão para se referir a imperativos é estritamente analógico e não visa, portanto, atribuir a proposições práticas certas propriedades que caracterizam os juízos cognitivos ou objetivos.

Esta constatação é igualmente válida para a aplicação de outros termos lógicos à filosofia prática kantiana. Com efeito, por um lado, Kant afirma também na $F M C$ que proposições práticas incondicionais valem com "prin- 
cipios práticos apodídicos" (Kant 1, IV: 415) e que estes são proposições práticas sintéticas e a priori. Por outro lado, afirma que imperativos hipotéticos são proposições práticas analíticas que podem ser subdivididas em assertóricas e problemáticas (Kant 1, IV: 415). Diante das definições já aduzidas anteriormente para os diferentes conceitos de imperativos na filosofia de Kant, torna-se relativamente fácil compreender qual o significado desses termos, também originalmente lógicos, na FMC.

Sabe-se, portanto, que a forma do imperativo categórico é um produto da razão prática pura e isso significa dizer que este tipo de imperativo é uma proposição prática que não deriva analiticamente o seu mandamento de qualquer querer pressuposto. Como produto da razão prática pura ele representa então uma proposição prática sintética e a priori. Consequentemente, a sua compreensão não envolve a representação de interesses particulares pressupostos como motivos do agir, independendo completamente da experiência - ou da representação de motivos sensíveis. O conceito de aprioridade em Kant é definido como um conceito rigoroso de universalidade, isto é que envolve não apenas validade universal, mas também necessidade. Por isto é compreensível o uso da expressão apodídico para se referir ao imperativo categórico. O termo é usualmente empregado para se referir à necessidade lógica envolvida em juízos analíticos, que são juízos cuja "(...) verdade tem de poder ser sempre conhecida suficientemente de acordo com o princípio da contradição" (Kant 1, IV: 106-7). Um enunciado é, portanto, analiticamente verdadeiro se sua negação implica uma contradição. Logo, todo enunciado analítico tem de ser a priori verdadeiro. Assim, o uso do termo apodídico para se referir ao imperativo categórico é impróprio de um ponto de vista meramente lógico, mas compreensível, admitindo-se que o objetivo de Kant é apenas enfatizar a aprioridade envolvida no seu conceito.

Com relação a imperativos hipotéticos, poder-se-ia argumentar que eles são analíticos, como afirma Kant, no sentido de que da mesma maneira que em juízos analíticos o conceito-predicado está contido (ou implicado logicamente) no conceito-sujeito, o desejo de realizar um fim deve incluir também o desejo de requerer o meio necessário para a realização daquele fim. Para um razoável conhecedor da filosofia prática kantiana é fácil, contudo, perceber que mais essa analogia com a filosofia teórica não pode ser rigorosamente simétrica. O problema para tanto consiste no conceito de querer racional, que nesse caso tem de ser a única ligação possível para as representações sensíveis contidas num imperativo hipotético. Com efeito, quem age racionalmente deve também, ao querer um fim $A$, querer o mandamento $B$ necessário para a efetivação do fim almejado. Isto quer dizer que podemos imaginar, por exemplo, uma situação na qual um determinado agente simplesmente manifesta desejos sem querer, entretanto, buscar as condições necessárias para a realização dos seus interesses particulares. É 
necessário então distinguir no interior da filosofia prática os conceitos de querer (Wollen) e desejar (wuenschen). O exercício da vontade (ou querer), supõe sempre uma decisão de agir em conformidade com regras práticas. Já o conceito kantiano de desejo está diretamente relacionado à natureza sensível do homem. O modelo de agir racional que Kant tem em mente é essencial para entender tal distinção. Esse modelo consiste, como já visto, na tese de que uma representação - seja ela sensível ou não - só pode se constituir numa razão, entendida como um motivo para o agir, se incorporado como conteúdo numa lei do querer, i. e. numa máxima. Portanto, ao contrário dos seres irracionais, não podemos ser dirigidos, por assim dizer, diretamente pelo sentimento de prazer associado às representações de objetos desejados. É possível afirmar então que o querer de um fim, i. e. a decisão de adotar uma proposição prática que representa para a vontade um objetivo como motivação para a realização de uma ação, deve incluir em seu significado o querer do meio necessário enquanto condição para a efetivação de um determinado fim particular. Logo, o termo analítico não tem aqui um significado correspondente ao do seu análogo puramente lógico.

E também a distinção entre imperativos hipotéticos assertóricos e problemáticos não tem uma relação absolutamente direta com a distinção entre juízos cognitivos assertóricos e problemáticos. A expressão assertórico, quando aplicada a imperativos, classifica certas proposições práticas condicionadas cujas representações de fins estão ligadas à natureza sensível do homem, mais precisamente à necessidade natural de busca da felicidade (Kant 1, V, p.45: „Gluecklich zu sein, ist notwendig das Verlangen jades vernuenftigen, aber end lichen Wesens und also ein unvermeidlicher Bestimmungsgrund seines Begehrungsvermoegens") - por exemplo a busca da manutenção de uma boa saúde. Kant denomina esses mandamentos "conselhos da prudência" (Ratschlaege der Klugheit). Ao contrário, o termo problemático refere-se a proposições práticas condicionadas cujos fins, muito embora sejam representações sensíveis, não podem ser considerados motivos sensíveis imprescindíveis - por exemplo, a escolha do melhor meio para realizar o conserto de uma máquina. Este tipo de mandamentos são denominados regras da destreza (Regeln der Geschicklichkeit). Assim, nos dois casos os termos lógicos transpostos para o campo prático se referem tãosomente ao tipo da exigência contida no mandamento y presente na forma "se queres $x$, faca $y$ ". No primeiro caso, o termo assertórico refere-se à necessidade envolvida no imperativo, mas apenas na medida em que um determinado agente considera um certo fim relevante para a sua felicidade. No segundo caso, o termo problemático se refere ao modo de proceder técnico mais adequado para a realização de fins particulares diversos e que não estão necessariamente relacionados à permanente busca humana pelo bem-estar. 
Os parágrafos acima mostram que na esfera da ética kantiana o uso de termos lógicos é puramente analógico, já que tais conceitos assumem um significado distinto quando aplicados a proposições práticas. No que tange à objeção de Butts feita à aplicação de categorias lógicas a proposições práticas, podemos dizer que ela suscita uma observação que ajuda a solucionar alguns problemas interpretativos sobre a antinomia da faculdade de julgar teleológica. Pois ele afirma, em particular, que princípios regulativos (em geral) não podem se contradizer porque eles não têm uma forma proposicional. Alguns dos principais estudiosos dessa antinomia a interpretam segundo a forma de uma contradição excludente entre máximas teóricas e regulativas da faculdade de julgar. Entretanto, se a afirmação de Butts está correta, as interpretações desses comentaristas não podem ter sentido, já que eles defendem uma espécie de oposição entre regras regulativas na CFJ. O que dizer então sobre a possibilidade de aplicação do princípio lógico da contradição a máximas das filosofias prática e teórica? Máximas em geral podem ou não se contradizer da mesma maneira que proposições?

O essencial do argumento que subjaz à afirmação de Butts parece ser que o principio da contradição - por exemplo: é impossível que $p$ e não-p sejam verdadeiros ao mesmo tempo e no mesmo respeito - é uma relação lógica que só pode subsistir entre proposições dotadas de um valor de verdade. Se esta afirmação é correta, visto que proposições práticas, diferentemente de juízos cognitivos, não têm um valor de verdade, não se pode falar em tese em máximas contraditórias na filosofia moral. Entendo no entanto que essa objeção pode ser rechaçada de duas maneiras que anulam a afirmação de Butts tanto no que tange a máximas práticas como no que concerne a máximas teóricas. Pois é possível perfeitamente [i] reformular o princípio da contradição de modo a estendê-lo a toda proposição que tenha condições de validade ou aceitabilidade; e [ii] mostrar que máximas em geral (inclusive proposições práticas, portanto) pressupõem proposições teóricas ou cognitivas - de tal modo que se pode dizer que duas proposições práticas se contradizem mutuamente se alguma de suas pressuposições teóricas se contradizem (p. ex.: o imperativo "abre a porta" pressupõe: "a porta está fechada", "você pode" (consegue, tem força para abrir a porta)).

No caso das máximas teóricas em questão, ou seja, as regras regulativas que em princípio podem gerar a suposta antinomia da faculdade de julgar, é digno de nota que o ponto [ii] é decisivo para a garantia da possibilidade da conflito. Segundo esse tópico, é preciso reconhecer que não apenas proposições práticas têm de pressupor proposições cognitivas nãocontraditórias para terem sua validade garantida, mas também máximas que são condições de possibilidade do conhecimento a título de máximas regulativas da faculdade de julgar. Se isso é verdadeiro, a possibilidade daquela contradição antinômica também tem de pressupor a satisfação de 
certas exigências teóricas. Assim, com respeito aos princípios do mecanismo e teleológico é fácil ver que a pressuposição teórica que tem de ser satisfeita para permitir a compatibilização dos mesmos é precisamente a validade objetiva das categorias do entendimento, em particular a validade do princípio da causalidade natural. Diante disso, é claro que as duas máximas da faculdade de julgar podem ser compatíveis, pois elas consistem em aplicações complementares do princípio da finalidade formal. Visto que este princípio foi deduzido na "Introdução" da CFJ como uma expressão da necessidade subjetiva que tem um intelecto finito no ato de conhecimento de uma determinada classe já constituída de substâncias, é forçoso reconhecer, portanto, que uma efetiva antinomia da faculdade de julgar só poderia ter lugar se aqueles princípios subjetivos modificassem suas respectivas formas. Desenvolver esta tese, contudo, ultrapassa os objetivos desse artigo.

CORDEIRO, Renato Valois. The Kantian concept of maxim and the solution of the antinomy of teleological judgment in the third Critique. Trans/Form/Ação, (São Paulo), v.30(2), 2007, p.135-149.

- ABSTRACT: The present paper attempts to clarify the Kantian concept of maxim. Its object is to provide an interpretation that places the assignment of different functions to this concept in the Kantian philosophy. The author explores also the consequences of his analysis for the solution of the antinomy of teleological judgment in the third Critique. At the heart of this antinomy is Kant's contention that all "semblance" (Anschein) on a conflict between the mechanistic and teleological maxims stems from the confusion of a principle of reflective with one of determinative judgment.

- KEYWORDS: Imperatives; maxims; objective practical principles; practical philosophy; reflective judgment; subjective practical principles; theoretical philosophy; transcendental philosophy.

\section{Referências bibliográficas}

ALLISON, H. Kant's Transcendental Idealism - An Interpretation and Defense. New Haven and London: Yale University Press, 1983.

BITTNER, R. "Máximas". In: Studia Kantiana - Revista da Sociedade Kant Brasileira, n.5, 2003.

BUTTS, R. Kant's Double Government Methodology. Boston, 1984, p.272-3.

EWERS, Michael. „Teleologie bei Hegel“. In: Ewers, M. Philosophie des Organismus in teleologischer und dialektischer Sicht. Münster: Lit Verlag (Bd. 3), 1986.

FLOYD, Juliet. „Herautonomy: Kant on Reflective Judgment and Systematicity“. In: Kants Ästhetik. Berlin: De Gruyter, 1998. 
FREUDIGER, Juerg. „Kants Schlussstein - wie die Teleologie die Einheit der Vernunft stiftet“. In: Kant-Studien, 87, Heft 1, 1996.

HEGEL, G. W. F. Wissenschaft der Logik. Frankfurt am Main: Suhrkamp, 1969.

KANT, I. Kants gesammelte Schriften - herausgegeben von der Deutschen Akademie der Wissenschaften. Berlin: Walter de Gruyter, 1902.

McLAUGHLIN, P. Kants Kritik der teleologischen Urteilskraft. Bonn: Bouvier, 1989.

PATZIG, G. „Die Logischen Formen praktischer Saetze in Kants Ethik“. In: PRAUSS, G. (ed.). Kant - Zur Deutung seiner Theorie von Erkennen und Handeln. Koeln: Kiepenheuer und Witsch, 1973.

TUGENDHAT, E. Logisch-semantische Propaedeutik. Stuttgart: Reclam, 1993. 